\title{
Wissler Simulations of a Liquid Cooled and Ventilation Garment (LCVG) for Extravehicular Activity (EVA)
}

\author{
Matthew Kesterson
}

Jacobs Sverdrup

\author{
Grant Bue and Luis Trevino
}

NASA Johnson Space Center

Copyright @ 2005 SAE International

\section{ABSTRACT}

In order to provide effective cooling for astronauts during extravehicular activities (EVAs), a liquid cooling and ventilation garment (LCVG) is used to remove heat by a series off tubes through which cooling water is circulated. To better predict the effectiveness of the LCG and determine possible modifications to improve performance, computer simulations dealing with the interaction of the cooling garment with the human body have been run using the Wissler Human Model.

Simulations have been conducted to predict the heat removal rate for various liquid cooled garment configurations. The current LCVG uses 48 cooling tubes woven into a fabric with cooling water flowing through the tubes. The purpose of the current project is to decrease the overall weight of the LCVG system. In order to achieve this weight reduction, advances in the garment heat removal rates need to be obtained. Currently, increasing the fabric's thermal conductivity along with also examining an increase in the cooling tube conductivity to more efficiently remove the excess heat generated during EVA is being simulated.

Initial trials varied cooling water temperature, water flow rate, garment conductivity, tube conductivity, and total number of cooling tubes in the LCVG. Results indicate that the total number of cooling tubes could be reduced to 22 and still achieve the desired heat removal rate of $361 \mathrm{~W}$. Further improvements are being made to the garment network used in the model to account for temperature gradients associated with the spacing of the cooling tubes over the surface of the garment.

\section{INTRODUCTION}

For various periods during space missions, astronauts utilize a LCVG in order to remove excess heat and to remain comfortable and productive. These suits are used in both extravehicular activities and upon vehicle re-entry. For future long-term/long-range missions (i.e., mars transit, base), mission cost savings can be achieved by a reduction in the system mass. To this end, a study has been initiated to examine possible advancements in heat removal capabilities of an advanced liquid cooling and ventilation garment.

Using new materials, specifically carbon nanotubes, which are known to have a high thermal conductivity, it was theorized that a new LCVG could be constructed with mass savings being achieved by a reduction in the number of cooling tubes used in the garment and by less water needed for the cooling effects

The current LCVG consists of a garment material that has small plastic tubing spread out over the surface of the garment. Water was circulated through these cooling tubes to remove heat from the garment. This heat removal process was further enhanced by an air ventilation process over the garment. In an effort to reduce the mass of the current cooling garment, efforts to redesign the LCVG have led to examining the effects of increasing the garment and tube thermal conductivities. A current guideline for the new LCVG is that the water coolant loop needs to achieve a heat removal rate of at least $361.1 \mathrm{~W}$ when the user's metabolic rate is $468.6 \mathrm{~W}$. 
Simulations using the Wissler model were performed for various garment thermal conductivities, cooling water flow rates, and total number of cooling tubes used in the overall LCVG. The baseline values for the current garment are list below in Table 1.

Table 1 - Baseline values for liquid-cooled garment operation.

\begin{tabular}{|l|l|}
\hline Number of Cooling Tubes & 48 \\
\hline Garment Thickness (mm) & 1.1 \\
\hline Garment Conductivity $(\mathrm{W} / \mathrm{m}-\mathrm{K})$ & 0.080 \\
\hline Tube Conductivity $(\mathrm{W} / \mathrm{m}-\mathrm{K})$ & 0.252 \\
\hline Garment-to-tube kA/L (W/K) & 0.032 \\
\hline Garment-to-skin kA/L (W/K) & 0.032 \\
\hline Cooling Water Temperature (C) & 18.33 \\
\hline Cooling Water Flow Rate (kg/hr) & 109.1 \\
\hline
\end{tabular}

The first issue that was seen from these initial parametric studies was that the garment thermal conductivity had little effect on the heat removal achieved by the overall LCVG. This can be seen in Figure 1. The chart shows the effect of garment conductivity on the heat removal rate of the liquid cooling tubes. The lower set of data points represents the heat removal rate using 16 cooling tubes at garment conductivities ranging from 0.08 to $0.86 \mathrm{~W} / \mathrm{m} \mathrm{K}$. The upper set of data points represents the results for the case of 38 cooling tubes. The same temperature dependence was seen for all other sets of cooling tubes tested. There was no significant difference when the cooling water flow rate, tube conductivity, or garment thickness was varied. This was in conflict to what had been seen previously with the SINDA/FLUINT simulations.

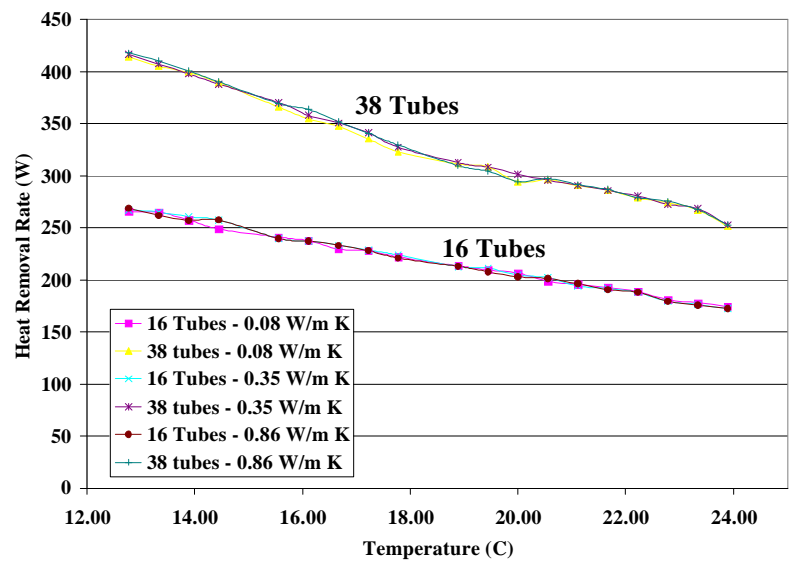

Figure 1 - Effect of garment conductivity on liquid cooling tube heat removal rate. Garment thickness, tube conductivity, and cooling water flow rate are the baseline values of $1.1 \mathrm{~mm}, 0.252 \mathrm{~W} / \mathrm{m} \mathrm{K}$, and $109.09 \mathrm{~kg} / \mathrm{hr}$ respectively.

While the Wissler simulation is accurate at predicting human metabolic responses, it has a lower fidelity for modeling the garment properties. The liquid cooling garment that was used in the Wissler model was a lumped model. Based on the number of cooling tubes in the overall garment, the amount of surface area available for heat transfer on each specific body element was calculated. When the calculation for the heat transfer through the cooling tubes was performed in the code, the program treats the multiple cooling tubes as one unit. The heat conduction in the garment was then treated as one dimensional, and lateral heat conduction was neglected. Therefore, there was a low confidence in the results for heat removal versus garment conductivity.

Another parameter that was varied in the simulations was the flow rate of water through the cooling tubes. Figure 2 shows the effect of the coolant water flow rate for various numbers of tubes. There was a decrease in the heat removal rate of $\sim 5 \%$ when the water flow rate was decreased from 109.09 to 63.64 $\mathrm{kg} / \mathrm{hr}$. This change in heat removal rate became less significant as the number of cooling tubes was decreased.

As the tube conductivity was increased by a factor of 10 , a $14 \%$ increase in the heat removal rate by the water loop was seen. For these cases, the garment to tube heat transfer coefficient started to become a limiting factor in how much heat the LCVG could remove.

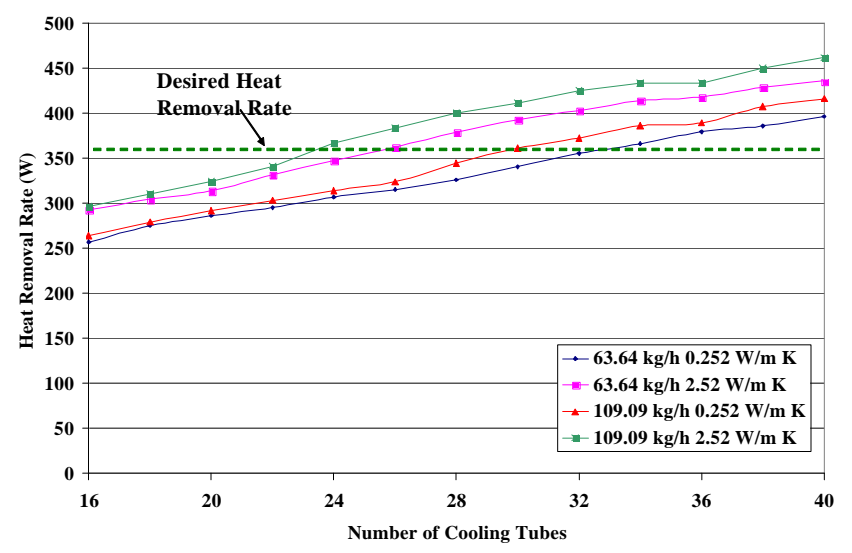

Figure 2 - Effect of coolant water flow rate and tube conductivity on the heat removal of the liquid coolant loop. Garment thickness and conductivity are $1.1 \mathrm{~mm}$ and 0.08 $\mathrm{W} / \mathrm{m} \mathrm{K}$ respectively.

\section{Original Wissler Results}

From the simulations conducted with the original Wissler model, the desired heat removal for the cooling tubes of $361 \mathrm{~W}$ was achieved with 22 cooling tubes with a garment thickness of $1.10 \mathrm{~mm}$, tube conductivity of $2.522 \mathrm{~W} / \mathrm{m} \mathrm{K}$, and a cooling water flow rate of 109.09 $\mathrm{kg} / \mathrm{hr}$. For the case of using 22 tubes, the desired heat removal rate was achieved, but the simulations predict that the person will be sweating and shivering slightly at 
the same time.

While a number of possible garment configurations existed that were able to achieve the desired heat removal rate for the liquid cooling loop, to determine the best available LCVG configuration, weight and comfort of the garment need to be taken into account.

\section{Modifications to the Wissler Model}

The original Wissler model consisted of 15 body elements. Each of these elements had 15 radial segments ranging from the core of the element to the outer skin layer, as depicted in Figure 3 . Additional clothing could be applied to these body elements with a maximum of 6 additional garment layers. Each of these garment layers was modeled as a single node.

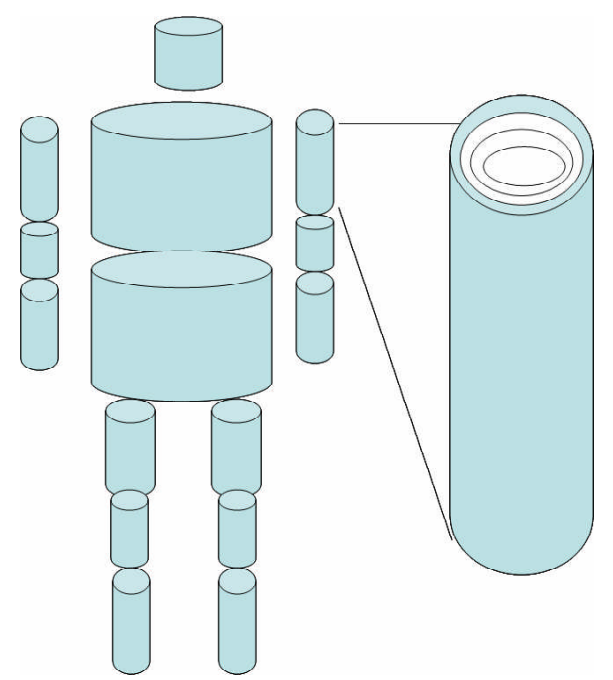

Figure 3 - Wissler body element schematic.

In order to obtain a higher level of detail for the heat transfer within the garment, two new simulation files were created. The first file was a subroutine called "Garm.f". This subroutine created a mesh of garment nodes over each of the body elements. The width of each node was fixed to be equal to the outer diameter of the cooling tubes.

In the original Wissler program, the body was divided into 15 elements: chest, abdomen, head, etc. Each of these elements was further subdivided into 15 radial segments, ranging from the inner core to the outer skin. A garment could also be applied to the outer skin layer. The garment layer was modeled as a sheet covering the body element and could be further subdivided into an additional 6 radial segments. Heat flux was only driven by temperature gradients between the radial segments and not laterally within the garment layer. The new "Garm.f" subroutine enabled temperature gradients to exist within each layer of the garment, and therefore heat transfer within the garment layer could be achieved. Figure 4 depicts the change made to the garment and liquid cooling layers between the original Wissler code and the code using the additional "Garm.f" subroutine.

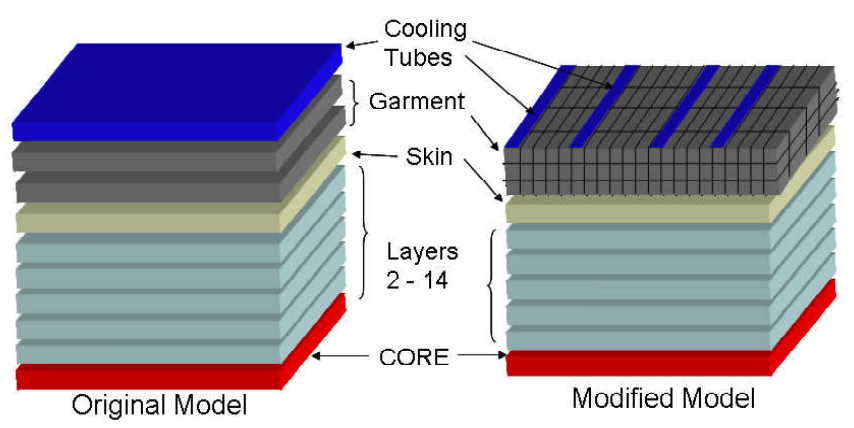

Figure 4 -Representation of modeled layers in the original Wissler code and the modified garment code.

The second file, entitled "LCG.inp", was a new user-specified input file. This file contained the garment thickness, garment wet and dry conductivities, the garment wet and dry specific heat, number of cooling tubes in the upper and lower body sections, thermal conductivity of the cooling tubes, inlet temperature of the cooling water, and the cooling water flow rate.

\section{Modified Wissler Simulations}

Simulations were started using the modified Wissler model. Due to time constraints, not all desired parametric simulations were conducted. Table 2 lists the variables that were used in the current set of modified Wissler simulations. Due to time constraints, variations in tube conductivity, and garment thickness have not yet been performed.

Table 2 - Parameters for Modified Wissler Parametric Simulations

\begin{tabular}{|l|l|}
\hline Number of Cooling Tubes & $24-40$ \\
\hline Garment Conductivity $(\mathrm{W} / \mathrm{m}-\mathrm{K})$ & $0.08-0.86$ \\
\hline Cooling Water Flow rate $(\mathrm{kg} / \mathrm{hr})$ & $63.5-109.1$ \\
\hline Tube Conductivity $(\mathrm{W} / \mathrm{m}-\mathrm{K})$ & 2.52 \\
\hline Cooling Water Temperature $\left({ }^{\circ} \mathrm{C}\right)$ & 12.78 \\
\hline
\end{tabular}

Using the modified Wissler model, a series of simulations were run with 24-40 cooling tubes over the range of garment conductivities $(0.080-0.865 \mathrm{~W} / \mathrm{m}-\mathrm{K})$ with the baseline flow rate of $109.1 \mathrm{~kg} / \mathrm{hr}$. The results are shown in Figure 5. As mentioned before, the original Wissler model predicted constant heat removal rate by liquid cooling for the various garment conductivities evaluated, with only a slight drop at the baseline conductivity value. The modified $W$ issler results not only show a heat removal dependence on garment conductivity, but also an improved performance over the 
original Wissler results at the higher conductivity values, shown in Figure 6.

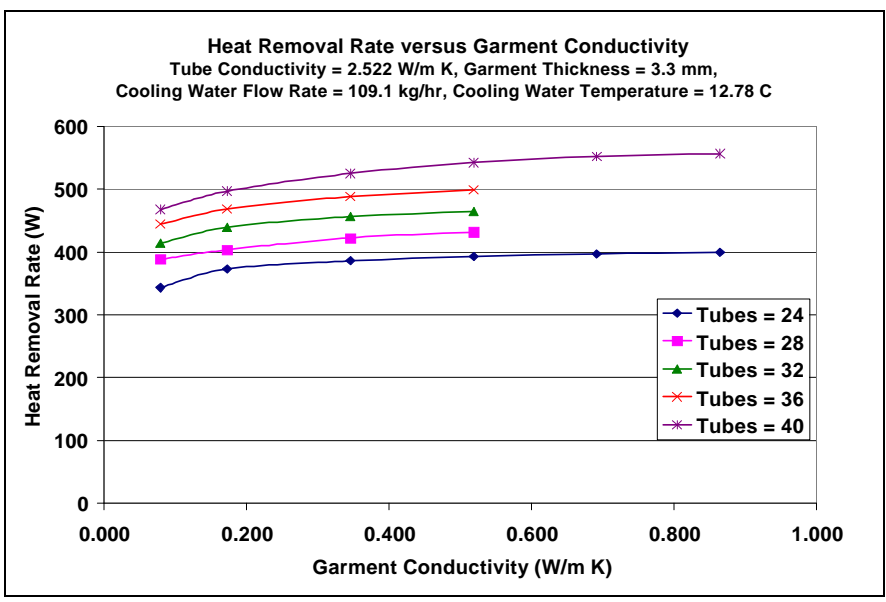

Figure 5 - Heat removal rate as a function of garment conductivity.

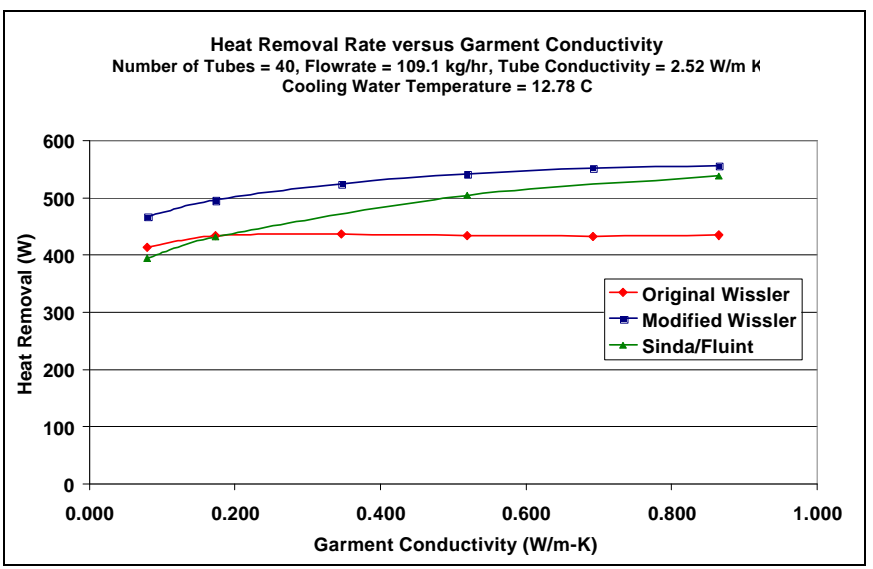

Figure 6 - Heat removal rate as a function of garment thermal conductivity for various simulation models.

Figure 7 shows the effect that the number of cooling tubes has on the heat removal capability of the LCVG. For the garment configuration (garment conductivity $=0.08 \mathrm{~W} / \mathrm{m}-\mathrm{K}$, garment thickness $=3.3$ $\mathrm{mm}$, water flow rate $=109.1 \mathrm{~kg} / \mathrm{hr}$, tube conductivity = $2.52 \mathrm{~W} / \mathrm{m}-\mathrm{K}$, and a cooling water temperature of 12.78 ${ }^{\circ} \mathrm{C}$ ), the modified Wissler study shows a heat removal rate of $388 \mathrm{~W}$ with 28 cooling tubes, surpassing the desired heat removal rate of $361 \mathrm{~W}$. As also seen in this chart, previous studies with the original Wissler and the SINDA/FLUINT models need 32 and 36 tubes respectively to achieve the desired heat removal rate.

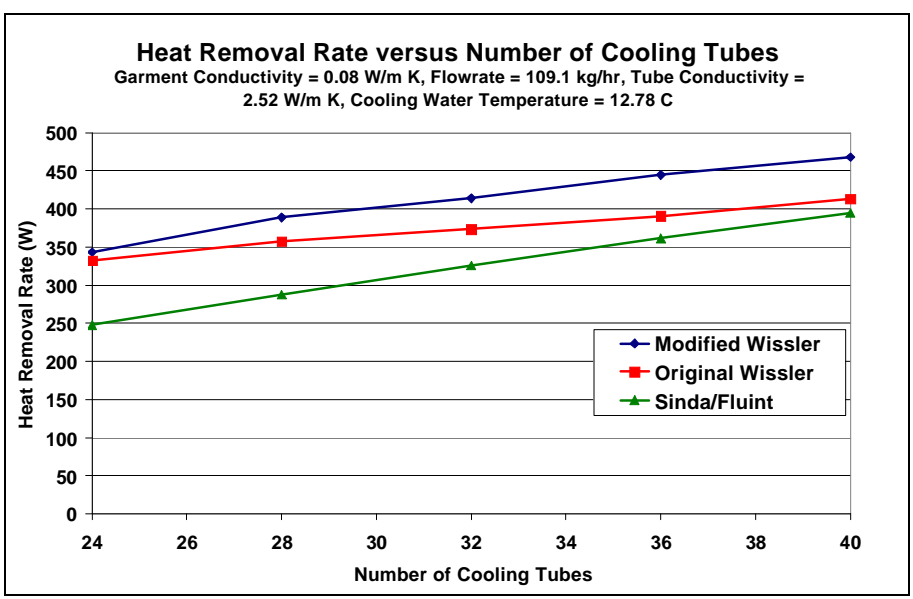

Figure 7 - Heat removal rate as a function of the number of cooling tubes in the LCVG for various simulation models.

In order to determine if a smaller pump could be utilized for the LCVG, simulations were conducted using water flow rates of 63.6 and $109.1 \mathrm{~kg} / \mathrm{hr}$ (baseline flow rate). Figure 8 shows the results from these simulations. A reduction in the liquid flow rate by $40 \%$ lowers the heat removal rate of the garment by $5 \%(28$ tubes) to $10 \%$ (40 tubes). The results shown are for a LCVG with the baseline garment conductivity of 0.08 $\mathrm{W} / \mathrm{m}-\mathrm{K}$. Further simulations are scheduled to determine the effect reducing the coolant flow rate will have on garments with higher thermal conductivity. At this reduced flow rate, the heat removal rate of $361.1 \mathrm{~W}$ can be achieved with 28 cooling tubes.

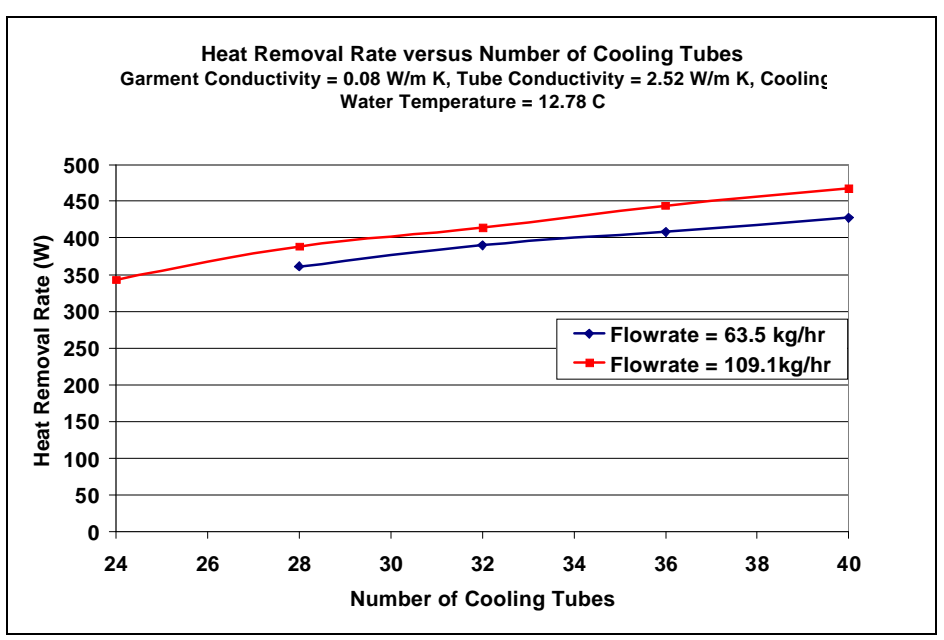

Figure 8 - Heat removal rate as a function of the number of cooling tubes for various cooling water flow rates using the modified Wissler model. 


\section{Conclusion}

The modified form of the Wissler model predicts an overall increase in LCVG performance over the original model due to the nodalization of the garment layers. This nodalization allows for the added effect of lateral heat conduction from the warm areas in the regions between cooling tubes to the regions that align with the cooling tubes themselves.

The model predicts that the total number of cooling tubes could be decreased to 28 with an associated decease in water flow rate. Many configurations exist that are predicted to achieve the necessary heat removal rate. From these configurations, the weight and comfort need to be evaluated to achieve the best possible LCVG.

\section{Acknowledgments}

Here is the Acknowledgment section. This is an optional section.

\section{CONTACT}

Matthew Kesterson

Jacobs Sverdrup

Mail Code: JE-5EB

P.O. Box 58447

Houston, TX 77258-8447

Matthew.kesterson@escg.jacobs.com

Phone (281) 461-5426 